\title{
Integrated Design Review Methodology for Critical Facilities Management and Maintenance
}

\author{
Igal M. Shohet ${ }^{1,2}$, Kun-Chi Wang ${ }^{2}$ and Sheng-Han Tung ${ }^{2}$
}

1 Department of Structural Engineering, Ben-Gurion University of the Negev, Beer Sheva, Israel

2 Department of Construction Engineering, Chaoyang University of Technology, Taiwan

\begin{abstract}
Critical facilities are expected to provide continuous performance in standard service conditions and in extreme events in particular. Continuity of performance is determined by the design redundancy, robustness and resilience. A framework for Integrated BIM based service life design review developed for planning of critical facilities. The framework aims at the execution of the design, construction, and commissioning of projects with whole life performance, operation, and costs planning. The methodology follows two phases: (I) Service life planning and (II) Design review. Service life planning is carried out through four stages: (1) Definition of the service regime; (2) Service Life Prediction of the building components; (3) Performance planning, and (4) Service Life Agreement. Design review (DR) is carried out for four building systems: structural safety and integrity, exterior envelope, interior finishing, and exterior infrastructures; and six electro-mechanical systems: Electric and power supply system, Water supply and sanitary, HVAC, Fire Protection, Elevators, and Communication and low voltage systems. DR follows four principles: (1) Durability; (2) Techno-economic service life planning; (3) Maintainability; and (4) Minimization of the Life Cycle Costs (LCC). A Design Review matrix developed for automation of the DR process: the DR matrix is composed of four leading key factors. Key leading factors are Durability, Maintainability, Service Life Planning and Design Guidelines. An integrated public-hospitality case study carried out and presented.
\end{abstract}

(c) 2020 The Authors. Published by Budapest University of Technology and Economics \& Diamond Congress Ltd Peer-review under responsibility of the Scientific Committee of the Creative Construction Conference 2020.

Keywords: BIM, briefing, critical facilities, maintenance, performance

\section{Introduction}

Integration between BIM and FM attains a potential for strengthening the core tasks of FM as well as delivering the BIM advantages to the commissioning stage. This includes: reducing the procurement costs, improving life cycle decision making, reducing costs due to waste, rework, and deterioration of components and systems, improving the safety and health of the occupants and the FM staff, and improving the endusers and stake holders satisfaction [1, 2]. Dixit et al. [3] researched 16 issues related to the integration of BIM and FM under four core categories: BIM-execution and informationmanagement, technology, cost and legal and contractual issues. The most significant issue for expediting the integration of BIM and FM was found to be involvement of FM in the project phases. Gurevich et al. [4] introduced a comprehensive BIM Adoption Impact Map (BIM AIM) as a four level gradual process composed of CAD (level-0), 2-D and 3-D (level-1), BIMs (Level-2), and iBIM integrating Life Cycle Asset Management (level-3). The authors found that comprehensive integration of BIM in the Life Cycle Management of a facility, implementation of BIM in the Design, Construction, Commissioning and maintenance of the facility can increase the probability of meeting the clients and end-users expectations of meeting the budget, the time, construction quality and performance of the facility. The study concludes that BIM can support a better project outcome by facilitating design review and acquiring improved performance in terms of lighting, ventilation, thermal comfort etc. Halmetoja [5] found that BIM can serve as an effective framework for building maintenance 
and operation, and that many of the services management can be delivered effectively when they will be implemented through the design and construction phases. This research also stresses that the integration of BIM into the life cycle management of the project will be effectively accomplished if FM will be integrated in the design phase.

\section{Literature review}

Kassem et al. [6] researched the implementation of BIM applications in FM through a case study of an academic campus. The authors figured out that BIM can improve FM processes due to improved information handover; improvement of the accuracy of FM data, improved accessibility of FM data and increase in the efficiency of work order execution. The authors found that the main barrier of BIM Implementation in FM are the lack of methodologies that demonstrate the tangible benefits of BIM in FM. This research indicates the need for BIM-FM methodologies such as design review. Ilter and Ergen [7] carried out a semantic review of the literature identifying BIM-FM input-output relations and exhibiting areas of focus as well as research gaps in the field. The authors recommended the development of BIMbased standard for the integration between FM and BIM databases. Development of specifications information exchanges in FM, as well as extending Industry Foundation Classes were also recommended to provide new properties related to FM. Matarneh, R. et al. [8] carried out a holistic review of the state-ofthe-art on the current information exchange process between BIM and FM and concluded that software interoperability remains a significant barrier for BIM-FM application. This gap requires the standardization of practical processes to integrate between maintenance, health, safety management, and BIM data. In a follow up research [9], the researchers identified eight core BIM applications to FM amongst them: facilities information systems, maintenance management, energy management, space management, and health and safety management.

Pärn et al. [10] state that the BIM trajectory in facilities management must address long-term strategic planning, improvement of the data integration and interoperability, and advanced performance management. Singh et al. [11] developed a framework for BIM-server multidisciplinary collaboration platform. Three categories of core operational technical requirements were defined amongst them are: design review. Tan et al. [12] carried out three case studies on the effective knowledge and information flow between the building construction and facilities management in the procurement of construction projects. The researchers proposed three Key Success Factors (KSF): OCC (Open Communication Chanel), SLF (Soft Landings Framework), and BIM. The authors concluded that integration between the three KSF attains a strong potential for enhanced information flow in the construction process.

\section{Research objectives}

The literature review reveals a wide gap in the implementation of the life cycle aspects planning throughout the delivery of projects in general and delivery of critical infrastructures in particular. The research objectives therefore focus on twofold courses.

\subsection{Integrated BIM and FM}

Development of an integrated BIM and FM framework for implementation of life cycle design and planning of construction projects in general and for critical facilities projects in particular. This framework aims at the execution of service life performance, operation and life cycle costs planning of the design, construction, and commissioning of projects.

\subsection{Life Cycle Costs, Facilities Management, and Design Review}

The second objective focuses on the integration of LCC approach and the Facilities Management planning at the design process through a structured design review methodology for life cycle performance design. This objective aims at the integration of durability, performance, continuity of performance, maintainability, and LCC at the design and throughout the procurement process of Critical Infrastructures. 


\section{Research methods}

\subsection{Integrated DR and BIM}

Integrated DR and BIM is developed in three phases: (a) The building characteristics including the building designed life cycle, its service regime and its environment; (b) the building parameters including its building and electro-mechanical composites, and (c) the last phase is the performance-based design principles for the selection of adequate solutions for each building systems. This inference adapts the design to the prevailing service conditions in accordance with the performance requirements and with IFC guidelines.

\subsection{Design review methodology}

The DR methodology is based on the connectivity linkages described in Table 1 presented here for the buildings' components (an elaborated matrix will be presented in the full journal paper). The building's components and systems are reviewed for the adaptation between the buildings design and FM considerations as follows: durability of the component with respect to the exposure and expected service regime, maintainability of the component, the design life cycle of the facility and the core design considerations referring to each particular component.

Table 1. Facility maintenance design considerations of building and electro-mechanical systems

\begin{tabular}{|c|c|c|c|}
\hline $\begin{array}{l}\text { System } \\
\text { Design } \\
\text { Considerations }\end{array}$ & Structure & Exterior Envelope & Interior Finishing \\
\hline Durability & $\begin{array}{l}\text { The concrete's compatibility to the } \\
\text { exposure conditions }\end{array}$ & $\begin{array}{l}\text { Durability based on the building's } \\
\text { surroundings, its height and } \\
\text { execution deviations. }\end{array}$ & $\begin{array}{l}\text { Compatibility to the service regime and to } \\
\text { the planned life span. Durable elements } \\
\text { to service regime and conditions }\end{array}$ \\
\hline Maintainability & $\begin{array}{l}\text { Drainage of the structure and the } \\
\text { exterior envelope. }\end{array}$ & $\begin{array}{l}\text { Replacement of elements and } \\
\text { components. }\end{array}$ & Maintenance accessibility to elements. \\
\hline $\begin{array}{l}\text { Designed Life } \\
\text { Cycle (DLC) }\end{array}$ & $\begin{array}{l}\text { Compatibility with exposure, } \\
\text { structural insulation based on the } \\
\text { surrounding environment and the } \\
\text { buildings criticality. }\end{array}$ & Predicted life cycle. & $\begin{array}{l}\text { Adapting elements' life spans to the } \\
\text { service regime and the service life, } \\
\text { integrating the systems in the interior } \\
\text { finishing. }\end{array}$ \\
\hline $\begin{array}{l}\text { Core Design } \\
\text { Guidelines }\end{array}$ & $\begin{array}{l}\text { Adaptability to exposure conditions, } \\
\text { Adaptability of the geometry to } \\
\text { maintenance and exposure } \\
\text { conditions }\end{array}$ & $\begin{array}{l}\text { Adaptability to exposure } \\
\text { conditions, accessibility to } \\
\text { maintenance, integration with the } \\
\text { E.M. systems }\end{array}$ & $\begin{array}{l}\text { Adaptability to service regime, } \\
\text { maintainability }\end{array}$ \\
\hline
\end{tabular}

\subsection{Architecture and reasoning of the DR model}

\subsubsection{Structure}

Three principles guides the design review of the structure in this research:

(a) Adaptability to the exposure conditions, i.e. suitability of the structural elements protection to exposure conditions;

(b) Adaptability of the structure to the exterior cladding components: e.g. : fixing details geometry and measurements in structure and exterior cladding; (c) Drainage details such as: cornice drip-edge.

\subsubsection{Exterior envelope}

Three profound criteria guides the exterior envelope FM design review covering: durability, maintainability, and integration with the structure and electro-mechanical systems.

(a) Durability and adaptability to the exposure conditions: this parameter is assessed with respect to the predicted service life of the exterior cladding for the particular exposure conditions: marine environment, and air-pollution. The decision criterion can be either minimum LCC or maximum Predicted Service Life; 
(b) Maintainability: assessed according to geometry of the exterior walls and accessibility for maintenance and repair using hanging or tube and coupler scaffoldings.

(c) Integration with the structure and electro-mechanical systems assessed by location of electromechanical equipment units such as location of chillers in roofs (safety and operational distances).

\subsubsection{Interior finishing}

The core criteria for the design review of interior finishing components are focused on durability in the service regime and maintainability as follows: Adaptability to the service regime (service regime is defined as light, standard, intensive, and extreme service conditions), this tool can be implemented for interior partitions, flooring (ceramic, concrete tiles, carpets, etc.), and interior doors. The second criterion is maintainability and is expressed in the case of interior finishing components by replace ability of the components.

\section{Case study}

\subsection{Outline of the building}

The case study in this research is an academic activity centre project located in Hsinchu in the north of Taiwan. The exposure conditions are standard. It is a RC structure with four above ground floors and two underground floors with a total floor area of 15,919 [sq.m.]. The seismic resistance of the structure is acquired by the elevators and the staircase cores. The basement floor of the case study is mainly where the parking lot and large electro-mechanical equipment units are placed. The ice water machine of the HVAC system and the generator of the power system backup are placed in the basement floor. The above-ground space includes restaurant, conference room, and guest houses, where are mainly equipped with airconditioning pipelines, fire protection pipelines, water supply and drainage pipes, and hot water pipes. This study applies the proposed model to the case project examining the durability, maintainability and redundancy of the building components to demonstrate and validate the feasibility of the proposed model.

\subsection{Integrated $D R$ and BIM}

The integration of BIM and DR can be discussed by the three aspects of Durability, Maintenance, Redundancy.

- Durability: the elevation of the pipeline in the power system is higher than that of the water supply pipeline, which can prevent damage to the power pipeline due to water leakage from the water supply and secure the durability of the pipelines systems.

- Maintenance: In the case study, due to the small area of some spaces, it may cause difficulties in equipment maintenance. With the help of the BIM model, sufficient space for maintenance personnel to maintain (such as the radius of gyration of electrical equipment) is reserved to improve the maintainability of building components.

- Redundancy: The basement tested in this case is where the electromechanical hosts are placed. If the various hosts are too close together, it will be impossible to expand other pipelines and equipment in the future. Therefore, the BIM model is used to assure sufficient expansion space in the design.

\subsection{Building components $D R$}

\subsubsection{Structural safety and stability}

The structural safety and stability is reviewed through seismic design, design for fire protection and for other scenarios should they be relevant. The review refers to seismic design (lateral loads) and resistance of the structural elements to fire events according to the classification of the building. 


\subsubsection{Exterior envelope}

Through the BIM model, the details of the doors and windows assessed to check the size and details (waterproofing, drainage, durability, and maintainability) of the doors and windows parts. When the door and window components are damaged, the parameters of the components can be quickly inquired through the BIM model. Therefore, it is also possible to judge the cause of easy damage by the model, and select a more suitable material at the place to reduce the frequency of breakdown events.

(a) Durability: In the case building, there is space reserved for the exterior wall to repair the leaking space, so as to increase the service life of the exterior envelope.

(b) Maintainability: the exterior wall cladding of the case building is made of marble, it needs to be cleaned routinely according to its condition. Therefore, the working platforms of the cleaning staff is considered, and whether the cleaning staff has enough space for cleaning during maintenance.

\section{- Roof drainage}

Due to the long rainfall time (the average rainfall is about $1,164 \mathrm{~mm}$ per year) at the area of the case building. When designing the case project, three drainage details are set on each part of the roof. The distance between each drainage is $4.4 \mathrm{~m}$ and the diameter of the pipe linking to the drainage is $100 \mathrm{~mm}$. By checking the pipe diameter during maintenance through BIM, the cause of the blockage or insufficient capacity can be carefully and rigorously assessed. When the pipeline needs to be replaced, the maintenance engineer can also get the size of the pipeline and check whether the size is suitable for being placed there. Detail of roof drainage scheme is shown in Figure 1.
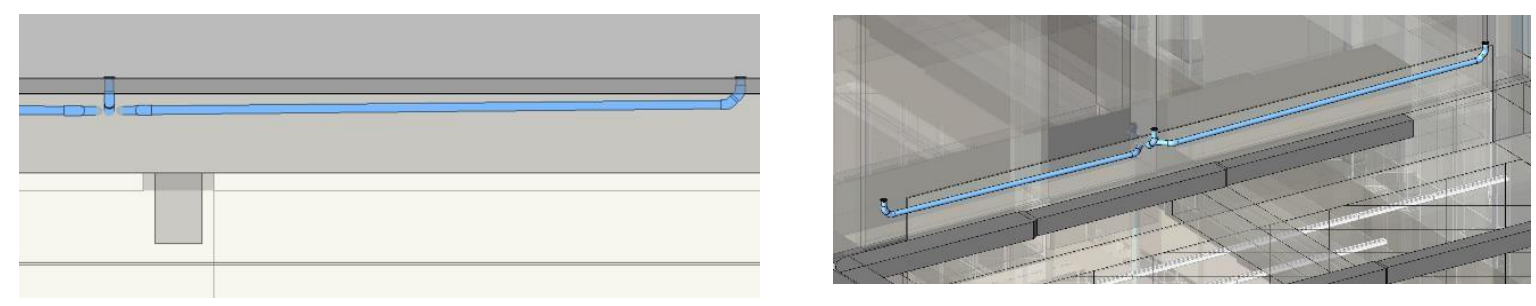

Figure 1. Detail of roof drainage scheme

\section{- Exterior cladding}

The curtain wall contains multiple pieces of information such as the crack resistance joints and the waterproofing details. In addition to the geometry of the curtain wall and the materials used, many parameters such as wind pressure resistance, earthquake resistance, air tightness, waterproofing, and deformation of the curtain wall affect the design principles. As the curtain wall project accounts for larger portion of the exterior envelope and the entire building, the parameters it contains also increase. If the information can be attached to the BIM model thorough the object classes parameters of the exterior wall object, it can assist in budget estimation, shorten the construction period, and find the most suitable repair plan and alternatives in subsequent maintenance. Facade detail of Curtain wall on the first floor is shown in Figure 2.

\section{- Exterior wall}

The exterior wall is reviewed according to the surrounding conditions of the building and the elevation, service life is assessed, and perform early detection of deterioration mechanisms to avoid excessive deterioration and avoid high maintenance expenditures. At the same time, consider the elevation of the exterior wall to learn about the maintainability of the place, and secure a maintenance accessibility to all exterior wall elements for proper and efficient maintenance.

\subsubsection{Interior finishing}

Through the BIM model, one can record the types of materials used in the interior decoration of buildings, such as interior partitions and paint colour numbers, door and window hardware materials, and so on. Through the information carried out in the proposed BIM model and framework, building parts can be quickly retrieved during maintenance in order to find a repair manufacturer. At the same time, through the 
function of BIM quantity calculation, when repaint or refurbish needed, one can quickly calculate the area for painting or decorating, in order to estimate the maintenance amount. Interior finishes of a typical guesthouse room are shown in Figure 3.

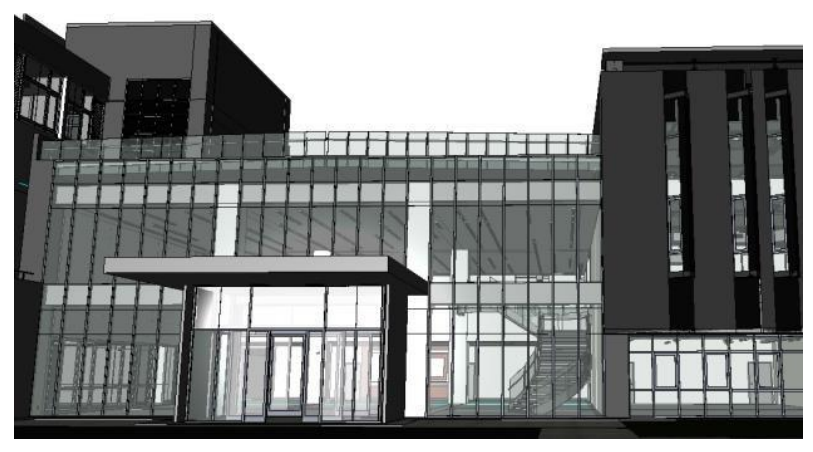

Figure 2. Facade detail of curtain wall on the first floor

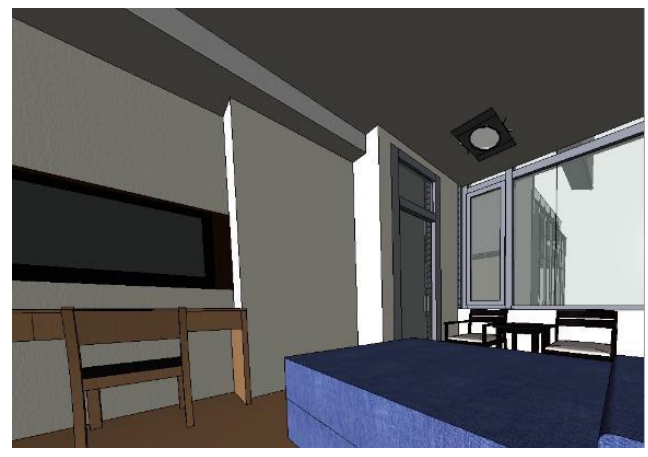

Figure 3. Interior finishes of a typical guesthouse room

\section{Conclusion}

The proposed framework for BIM Facilities Management and Maintenance Design Review for Critical Facilities lays the ground for comprehensive development of the BIM tools towards an integrated interface between durability, maintainability and Life Cycle Management using IFC class. The proposed framework and methodology paves the way for the interoperability in BIM to integrate Knowledge based IT-based design review tools for project life cycle design.

\section{Acknowledgements}

The authors thank several practitioners from the National Synchrotron Radiation Research Center in Taiwan, as well as many students from Chaoyang University of Technology and National Chiao Tung University for assisting in the development the BIM model.

\section{References}

[1] Sanhudo, L., Ramos, N. M. M., Martins Poças, J., Almeida, R. M. S. F., Barreira, E., Lurdes Simões, M., and Cardoso, V. (2018). "Building information modeling for energy retrofitting - A review." Renewable and Sustainable Energy Reviews, 89 249-260, https://doi.org/10.1016/j.rser.2018.03.064

[2] Farghaly, K., Abanda, F. H., Vidalakis, C., and Wood, G. (2018). "Taxonomy for BIM and Asset Management Semantic Interoperability." Journal of Management in Engineering, 34(4), 4018012, https://doi.org/10.1061/(ASCE)ME.19435479.0000610.

[3] Dixit, M. K., Venkatraj, V., Ostadalimakhmalbaf, M., Pariafsai, F., and Lavy, S. (2019). "Integration of facility management and building information modeling (BIM)." Facilities, 37(7/8), 455-483., https://doi.org/10.1108/F-03-2018-0043.

[4] Gurevich, U., Sacks, R., and Shrestha, P. (2017). "BIM adoption by public facility agencies: impacts on occupant value." Building Research \& Information, 45(6), 610-630, https://doi.org/10.1080/09613218.2017.1289029

[5] Halmetoja, E. (2019). "The conditions data model supporting building information models in facility management." Facilities, 37(7/8), 484-501, https://doi.org/10.1108/F-11-2017-0112.

[6] Kassem, M., Kelly, G., Dawood, N., Serginson, M., and Lockley, S. (2015). "BIM in facilities management applications: a case study of a large university complex." Built Environment Project and Asset Management, 5(3), 261-277, https://doi.org/10.1108/BEPAM-022014-0011/.

[7] Ilter, D., and Ergen, E. (2015). "BIM for building refurbishment and maintenance: current status and research directions." Structural Survey, 33(3), 228-256, https://doi.org/10.1108/SS-02-2015-0008.

[8] Matarneh, R., Matarneh, S. T., Danso-Amoako, M., Al-Bizri, S., and Gaterell, M. (2019). "Building information modeling for facilities management: A literature review and future research directions." Journal of Building Engineering, 24 100755, https://doi.org/10.1016/j.jobe.2019.100755.

[9] Matarneh, S., Danso-Amoako, M., Al-Bizri, S., Gaterell, M., and Matarneh, R. (2019). "BIM-based facilities information: streamlining the information exchange process." Journal of Engineering, Design and Technology, 17(6), 1304-1322. https://doi.org/10.1108/JEDT-02-2019-0048.

[10] Pärn, E. A., Edwards, D. J., and Sing, M. C. P. (2017). "The building information modelling trajectory in facilities management: A review." Automation in Construction, 75 45-55. https://doi.org/10.1016/j.autcon.2016.12.003.

[11] Singh, V., Gu, N., and Wang, X. (2011). "A theoretical framework of a BIM-based multi-disciplinary collaboration platform." Automation in Construction, 20(2), 134-144, https://doi.org/10.1016/j.autcon.2010.09.011.

[12] Tan, A. Z. T., Zaman, A., and Sutrisna, M. (2018). "Enabling an effective knowledge and information flow between the phases of building construction and facilities management." Facilities, 36(3/4), 151-170, https://doi.org/10.1108/F-03-2016-0028. 